\title{
Is there really eye damage in COVID-19?
}

\section{¿Realmente existe daño ocular en la COVID-19?}

\author{
Camila A. Martinez-Cornejo* and Angel del R. Tejada-Sihuin \\ Escuela de Medicina Humana, Universidad Privada San Juan Bautista, Chincha, Peru
}

\section{Dear Editor,}

As is known, SARS-CoV causes eye disease in some animals and due to its pathogenesis it was considered that it could cause similar damage in humans, although there was no evidence ${ }^{1}$.

In 2004, a new coronavirus (HCoV-NL63) was discovered, isolated in a 7-month-old boy who presented conjunctivitis, and later, in a study in France with children with this same coronavirus, it was found that $17 \%$ developed the same disease ${ }^{2}$.

SARS-CoV-2 causes respiratory failure, but there were no reports of eye damage. However, as its genome is $75-80 \%$ similar to that of SARS-CoV and $40 \%$ to MERS, which generated ocular alterations (redness, increased tear secretions), similar manifestations were expected $^{2}$. On January 22, 2020, Guangfa Wang, a physician, developed conjunctivitis during an inspection in Wuhan, and subsequently tested positive for SARSCoV-2, but recovered from the infection' ${ }^{1}$.

Ocular transmission is possible because the eye is connected to the airway through the nasolacrimal duct ${ }^{2,3}$. According to pathophysiology, direct injury to the ocular structures by the ACE-2 receptor has been described in the aqueous humor, ciliary body and adjacent structures, and there may also be indirect injury by release of cytokines due to the systemic inflammatory response ${ }^{3}$.

In 2020 studies it was detected that $30 \%$ of patients with COVID-19 developed ocular manifestations, such as conjunctivitis, chemosis, lacrimation, eye pain, etc., the most frequent being conjunctivitis ${ }^{2,3}$. In one study, five cases of oculomotor palsy caused by limited abduction of the sixth cranial nerve were described, followed by incomplete involvement of the third nerve, with diplopia or blurred vision ${ }^{3}$.

For a diagnostic approach, the polymerase chain reaction test was performed with tear samples, which was positive in some patients who had a severe systemic infection, being an indicator of poor prognosis'; biomicroscopy and optical coherence tomography were also used ${ }^{3}$.

Treatment with extended corticosteroid therapy could increase the risk of ocular hypertension and cataracts, while the use of macrolides has caused blurred vision and ocular pain, and antimalarials have produced ciliary body dysfunction and retinopathy ${ }^{1,3}$. Different committees commented on the possible risk of suffering ischemic optic neuropathy, since the prone position improves arterial oxygenation to areas of the lungs, but could induce ischemic processes; however, the benefit is greater than the complications ${ }^{2}$.

Therefore, it is concluded that the new coronavirus has ocular consequences that have been manifested in a small group of patients. More studies are still needed to include ocular manifestations among the symptoms of COVID-19, but it is important to consider the proper use of protective equipment, such as safety glasses, for exposed health personnel, and thus avoid possible infections through the ocular pathway. In case of contracting the infection, appropriate treatment should be administered to avoid possible ophthalmological complications. (http://creativecommons.org/licenses/by-nc-nd/4.0/). 


\section{Funding}

The authors received no funding for this publication.

\section{Conflicts of interest}

The authors declare no conflicts of interest.

\section{Ethical disclosures}

Protection of human and animal subjects. The authors declare that no experiments were performed on humans or animals for this study.
Confidentiality of data. The authors declare that no patient data appear in this article.

Right to privacy and informed consent. The authors declare that no patient data appear in this article.

\section{References}

1. Seah I, Agrawal R. Can the coronavirus disease 2019 (COVID-19) affect the eyes? A review of coronaviruses and ocular implications in humans and animals. Ocul Immunol Inflamm. 2020;28:391-5.

2. Bartolomé-Pérez F, Sánchez Quirós J. Manifestaciones oftalmológicas del SARS-CoV-2: revisión de la literatura. Arch Soc Esp Oftalmol. 2020:96:32-40.

3. Shuman-Betancourt I, Pérez-Mola K. La COVID-19 y sus consecuencias en el sistema ocular. Rev Inf Cient. 2020;99:284-92. 